CLINICAL STUDY

\title{
Pharmacokinetic and pharmacodynamic profile of a new sustained-release GH formulation, LB03002, in children with GH deficiency
}

\author{
Ferenc Peter, Conrad Savoy ${ }^{1}$, Hyi-Jeong $\mathrm{Ji}^{2}$, Mihaly Juhasz ${ }^{3}$, Martin Bidlingmaier ${ }^{4}$ and Paul Saenger ${ }^{5}$ \\ Buda Children's Hospital, Budapest, Hungary, ${ }^{1}$ BioPartners GmbH, Baar, Switzerland, ${ }^{2}$ LG Life Sciences, Seoul, Republic of Korea, ${ }^{3}$ Accelsiors Clinical \\ Study Services, Budapest, Hungary, ${ }^{4}$ Ludwig-Maximilians University, Munich, Germany and ${ }^{5}$ Department of Pediatrics, Albert Einstein College of \\ Medicine, Bronx, New York 10467, USA \\ (Correspondence should be addressed to P Saenger; Email: phsaenger@aol.com)
}

\begin{abstract}
Objective: LB03002 is a novel, sustained-release recombinant human GH, developed for once-a-week s.c. injection. To evaluate the suitability for long-term GH replacement therapy in children with GH deficiency (GHD), the present study assessed the pharmacokinetic (PK) and pharmacodynamic (PD) profiles of LBO3002 at three doses.

Study design and patients: The randomised, comparator-controlled, assessor-blinded, phase II study assessed 37 (24 boys, 13 girls) pre-pubertal, GH-naïve children with GHD, in 11 European centres, for PK and PD analyses. GH, IGF1 and IGFBP3 concentrations were measured following the last daily GH dose and the first and 13th once-a-week administration of LB03002 at doses of $0.2,0.5$ or $0.7 \mathrm{mg} / \mathrm{kg}$. Results: $\mathrm{GH}_{\mathrm{m}_{\max }}$ values after the three doses of LB03002 were increased up to fourfold, with a clear dose proportionality. For each LB03002 dose, GH area under the concentration versus time curve did not increase from the first to 13th (month 3) administration, indicating no accumulation of circulating GH. IGF1 $C_{\max }$ showed a progressive increase during LB03002 administration. Conversely, IGFBP 3 showed a rapid increase in $C_{\text {max }}$. IGF1 SDS were fully normalised after 3 months of treatment, whereas IGFBP3 SDS were already in the normal range for all the three LB03002 dosages after 1 week.

Conclusions: At the doses used, LB03002 has a suitable profile for long-term treatment to promote growth in children with GHD. The quantitative changes in IGF1 and IGFBP 3 indicate adequate stimulation of the IGF system by LB03002 and the pattern of increase is comparable with that seen in GHD children in a standard IGF1 generation test using daily GH.
\end{abstract}

European Journal of Endocrinology 160 349-355

\section{Introduction}

Recombinant human GH (rhGH) is primarily used to replace $\mathrm{GH}$ action in hypopituitary patients with $\mathrm{GH}$ deficiency (GHD), in children to promote GH-dependent growth and in adults to correct GHD-induced metabolic abnormalities. To exert these effects over the long term, rhGH has to be administered by daily s.c. injections, and treatment modalities and algorithms in growing children are now well established (1). However, daily injections represent a real burden to patients and to overcome this limitation, long-acting preparations of GH $(2-5)$ or, more recently, also of GHRH $(6,7)$ have been developed and tested in both children $(2,3)$ and adults (8) with GHD. At present, none of these products is commercially available.

LB03002 is a new subcutaneously administered sustained-release GH suspension of microparticles, consisting of GH incorporated into a matrix of sodium hyaluronidate and lecithin, which are dispersed in an oil base of medium-chain triglycerides (MCTs) before injection. LB03002 and rhGH used in the formulation originate from LG Life Sciences (Seoul, South Korea). rhGH is manufactured utilising the yeast Saccharomyces cerevisiae as the expression system. The resulting rhGH molecule has a primary structure that is identical to that of endogenous $22 \mathrm{kD}$ pituitary $\mathrm{GH}$ and showed comparable pharmacological profile and biological actions with other marketed rhGH brands (9). In an earlier study (10), we analysed the pharmacokinetic (PK) and pharmacodynamic (PD) properties of the sustained-release GH formulation, LB03002, in GHdeficient adults and showed a profile suitable for clinical use. We now report the PK and PD profiles of the same preparation in GH-naïve children with GHD, which were evaluated during the initial 3 months of a study assessing the 1- and 2-year efficacy and safety of LB03002. 


\section{Patients and methods}

\section{Patients and study design}

This was an assessor-blinded, randomised, comparatorcontrolled, multicentre phase II study in pre-pubertal GH-naïve children with GHD. The study protocol had two main objectives: define the PK/PD profile of the new sustained-release GH formulation (LB03002) in this population, and, based on the results obtained, establish the optimal dose to stimulate adequate long-term longitudinal growth. In the present report, we describe the results of the initial 3-month PK/PD study phase. Overall, 52 patients with established GHD (height $\leq-2$ S.D., height velocity $\leq-1$ S.D. and a GH peak $<7.0 \mu \mathrm{g} / \mathrm{l}$ in two different $\mathrm{GH}$ stimulation tests) from 11 centres in different European countries were enrolled into the study, and 37 patients with an age of $6.5 \pm 2.1$ years participated in the PK/PD study. Demographic parameters of the patients are summarised in Table 1.

All patients initially received a commercially available rhGH preparation (Genotropin) at a daily replacement dose of $0.03 \mathrm{mg} / \mathrm{kg}$ for 7 days. After a 3-week washout period, the patients were randomised to one of the three different doses of LB03002 once a week (group 1: $0.2 \mathrm{mg} / \mathrm{kg}$, group 2: $0.5 \mathrm{mg} / \mathrm{kg}$, group $3: 0.7 \mathrm{mg} / \mathrm{kg}$ ) for a period of 3 months. The PK/PD profile of dailyinjected GH was assessed on day 7 of Genotropin treatment, and that of the sustained-release formulation during the first and last weekly injection of LB03002 (13th dose at month 3). Safety assessments included recording of adverse events, regular monitoring of vital signs, clinical chemistry and assessment of injection site observations. Informed consent and assent respectively were obtained from all participants and/or their guardians; the protocol was approved by the local ethical committee and the study was conducted according to the declaration of Helsinki.

LB03002 was provided as dry powder in vials containing the equivalent of $12 \mathrm{mg}$ of rhGH and prior to injection was reconstituted with $0.6 \mathrm{ml}$ of MCT, producing a stable, homogeneous suspension of rhGH at a concentration of $20 \mathrm{mg} / \mathrm{ml}$. The comparator product genotropin was given by once-daily s.c. injection using the Genotropin Pen delivery device, containing $5.3 \mathrm{mg}$ rhGH in $0.3 \% \mathrm{~m}$-cresol, mannitol and water for injection.

\section{PK/PD assessments}

For the PK/PD profile of daily GH, blood samples were taken for GH measurement at 0.5, 0, 1, 2, 3, 4, 6, 8, 10, $12,16,20$ and $24 \mathrm{~h}$ after dosing and for IGF1 and IGFBP3 measurement at 0.5, 6, 12, 16, 24, 48, 96 and $168 \mathrm{~h}$. For the PK and PD profile of LB03002, samples were taken at $0,6,12,16,24,36,48,72,120$ and $168 \mathrm{~h}$ after injection. PK parameters for GH included the observed maximum serum concentration $\left(C_{\max }\right)$, the sample time at which $C_{\max }$ was observed $\left(T_{\max }\right)$, the half-life $\left(T_{1 / 2}\right)$ and the area under the concentration versus time curve (AUC). AUC was calculated using the trapezoidal rule until the value was below the limit of quantification (LOQ) and was assessed as the actual value and AUC normalised by dose (AUC/dose).

For PD parameters, IGF1 and IGFBP3, the variables $C_{\text {max }}, T_{\text {max }}, A U C$ and dose-normalised AUC were evaluated, similar to $\mathrm{GH}$ assessments. Mean daily exposure was calculated by dividing the AUC by 7 days. IGF1 and IGFBP3 concentrations were also converted to SDS by reference to the respective methodspecific normative data from a normal healthy population $(11,12)$.

All assays for PK and PD assessments were performed at a central laboratory (Endocrine Research Laboratories, Ludwig-Maximilians University, Munich, Germany). Serum concentrations of GH and IGF1 were both measured using an automated chemiluminescent assay system (Nichols Advantage, Nichols Institute Diagnostics, Bad Nauheim, Germany). For GH measurement, within-assay coefficient of variation $(\mathrm{CV})$

Table 1 Baseline demographics and clinical data.

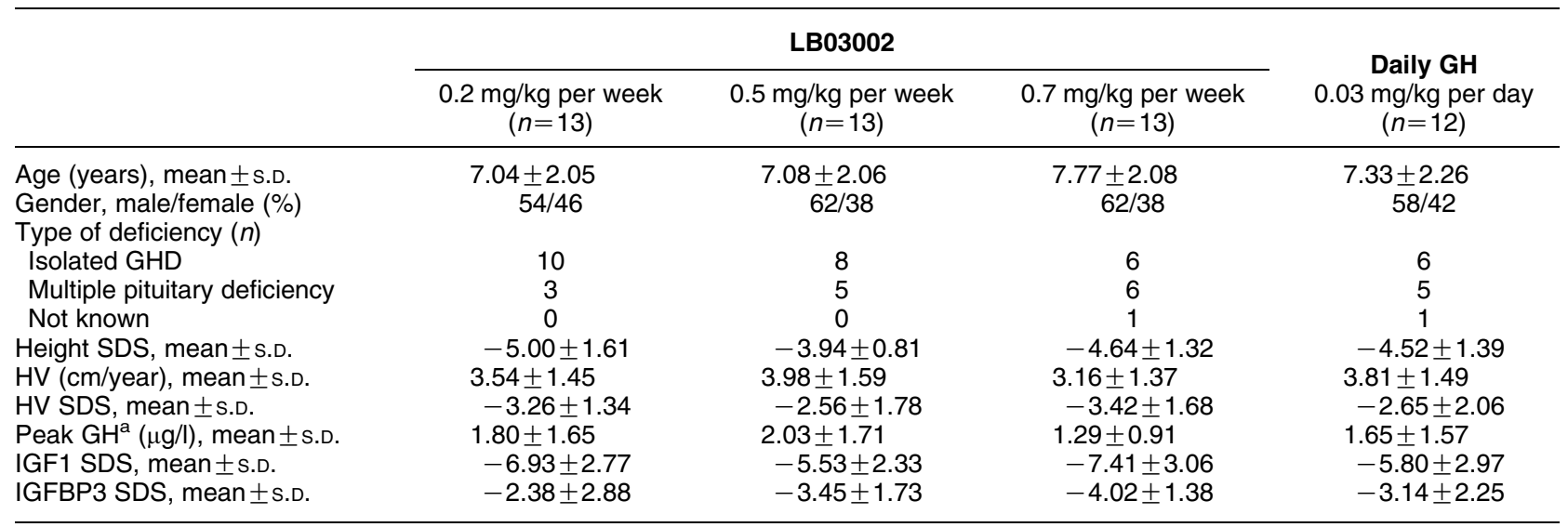

${ }^{\mathrm{a}}$ Mean from two stimulation tests. 
was $3.5,2.2$ and $2.9 \%$ at concentrations of $1.4,10.5$ and $28.0 \mu \mathrm{g} / \mathrm{l}$ respectively. Between-assay variation at the same concentrations was $7.9,2.7$ and $5.9 \%$ respectively. The LOQ was $0.2 \mu \mathrm{g} / \mathrm{l}$ and the linear working range $0.2-50 \mu \mathrm{g} / \mathrm{l}$. For the IGF 1 measurement, the intra-assay $\mathrm{CV}$ was $11.5,5.1$ and $3.5 \%$ at concentrations of 42,262 and $522 \mu \mathrm{g} / \mathrm{l}$ respectively. At the same concentrations, between-assay $\mathrm{CV}$ was 10.6, 10.6 and $10.2 \%$; the LOQ was $1 \mu \mathrm{g} / \mathrm{l}$ and the linear range $10-1000 \mu \mathrm{g} / \mathrm{l}$.

Serum concentrations of IGFBP3 were determined using the automated Immulite 2000 chemiluminescence assay system (DPC Biermann, Bad Nauheim, Germany). At concentrations of 1750 , 4400 and $5500 \mu \mathrm{g} / \mathrm{l}$, the intra-assay CV was $2.8,2.4$ and $1.8 \%$ respectively, and between-assay $\mathrm{CV}$ was 2.9 , 5.9 and $3.3 \%$ respectively. The LOQ was $500 \mu \mathrm{g} / \mathrm{l}$ and the linear range 500-10 000 $\mu \mathrm{g} / \mathrm{l}$. Age- and sexadjusted reference ranges for this method have been published (12).

For all PK and PD parameters, mean values, S.D. and 95\% confidence intervals (CI) were estimated. All values are presented as means with S.D., and those in tables are presented as means with $95 \% \mathrm{CI}$.

\section{Results}

\section{PK profile of GH}

The PK profiles of GH in the three groups dosed with LB03002 are shown for the 13th dose in Fig. 1. Baseline GH levels were below $1 \mu \mathrm{g} / \mathrm{l}$ in all patients, rose rapidly after the administration of the daily $\mathrm{GH}$ formulation at $0.03 \mathrm{mg} / \mathrm{kg}$ and returned to pre-dose levels within $24 \mathrm{~h}$. After the administration of LB03002, serum GH concentrations showed a delayed and variably extended peak at $12-24 \mathrm{~h}$ after the dosing. Concentrations remained elevated through $24 \mathrm{~h}$ and then gradually

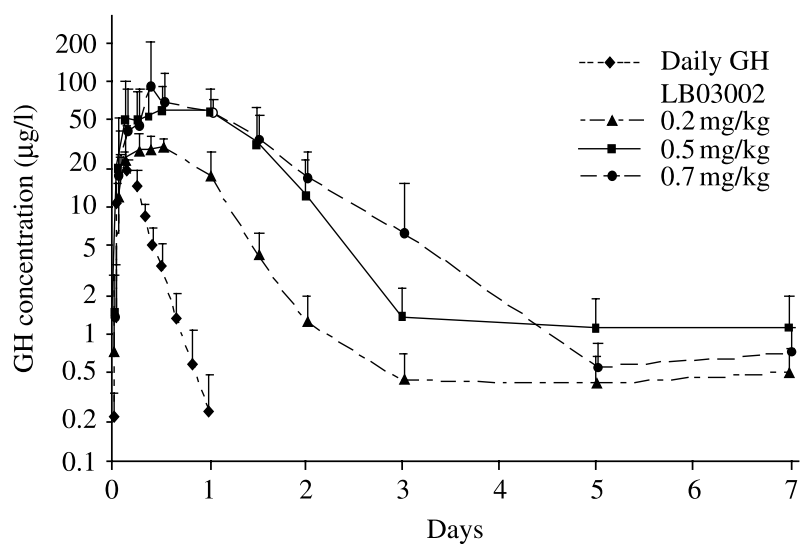

Figure 1 Serum GH levels after the administration of daily GH and after the last weekly administration of LB03002 at doses of $0.2,0.5$ and $0.7 \mathrm{mg} / \mathrm{kg}$; GH levels are plotted on a logarithmic scale as group arithmetic mean+S.D. declined; levels were not back to pre-dose levels until $72 \mathrm{~h}$ for the 0.2 and 0.5 doses, and until $120 \mathrm{~h}$ for the $0.7 \mathrm{mg} / \mathrm{kg}$ dose.

The PK parameters for daily GH and LB03002 are summarised in Table 2 . At the end of study period 1 , PK values for daily $\mathrm{GH}$ were comparable in all the three groups, although patients in group 2 showed a greater $C_{\text {max }}$ and AUC than the patients in the other two groups. With the LB03002 dosing of the three groups in period 2, after the first and 13th LB03002 administration, an extended peak was seen with an average $T_{\max }$ ranging between 10- and 20-h post-dose, which was the longest after the first $0.7 \mathrm{mg} / \mathrm{kg}$ dose. $C_{\max }$ increased in a doseproportional way, although for the $0.7 \mathrm{mg} / \mathrm{kg}$ dose it was slightly lower after the first administration. AUC increased proportionally in the dose range investigated, and mean AUC values after the first and 13th dose (i.e. within 3 months of treatment initiation) did not differ, indicating that no accumulation of $\mathrm{GH}$ released from once-weekly LB03002 occurred over the dose range studied. For all the three LB03002 dose groups, dosenormalised AUC (AUC/dose) was comparable, but somewhat lower than the AUC following the injection of daily GH. Mean $T_{1 / 2}$ calculated for LB03002 was in the range of 9.3-12.0 $\mathrm{h}$ and shown to be consistent for the three different dose groups and across the PK profiles taken after the first and 13th dose.

\section{PD changes}

IGF1-related parameters are summarised in Table 3. In the three treatment groups, baseline IGF1 values ranged from $14.8 \pm 14.1$ to $20.2 \pm 20.1 \mu \mathrm{g} / \mathrm{l}$. Median $T_{\max }$ values for IGF1 after daily GH were $12-16 \mathrm{~h}$ and ranged from 36 to $72 \mathrm{~h}$ after LB03002 administration, consistent with the prolonged release of GH from the sustained-release formulation. This resulted in an IGF1 profile with an extended peak after $\sim 48 \mathrm{~h}$ and a gradual return to pre-dosing levels by the end of the dosing interval. After the first administration of LB03002, the dose dependency of the IGF1 response was not very pronounced, with the $0.5 \mathrm{mg} / \mathrm{kg} \mathrm{LB03002}$ group having the lowest $C_{\max }$ and AUC values. However, with continued administration of LB03002, the effect on IGF1 induction became dose dependent across all the three dose groups. After 3 months, median IGF1 AUC values were increased over baseline by 52, 258 and $352 \%$, and $C_{\max }$ by 93,250 and $277 \%$, for the three dose groups respectively (Fig. 2). These relative increases were dose related, but not directly dose proportional.

IGFBP 3 levels for the three dose groups are shown in Fig. 3. The profile of IGFBP3 was somewhat different because the increase in $C_{\max }$ values after LB03002 administration was more rapid and less progressive than that for IGF1. To examine this difference, baseline IGF1 and IGFBP3 values as well as their mean peak concentration values after the first and last 
Table 2 Serum GH pharmacokinetic parameters of daily GH (day 7 of treatment) and of LB03002 (first and last once-weekly administration) at doses of $0.2,0.5$ and $0.7 \mathrm{mg} / \mathrm{kg}$; values are mean (approximate $95 \% \mathrm{Cl}$ ).

\begin{tabular}{|c|c|c|c|}
\hline & $\begin{array}{c}\text { Group 1 } \\
0.2 \mathrm{mg} / \mathrm{kg} \text { dose }(n=10)\end{array}$ & $\begin{array}{c}\text { Group 2 } \\
0.5 \mathrm{mg} / \mathrm{kg} \text { dose }(n=10)\end{array}$ & $\begin{array}{c}\text { Group 3 } \\
0.7 \mathrm{mg} / \mathrm{kg} \text { dose }(n=8)\end{array}$ \\
\hline \multicolumn{3}{|l|}{ Daily rhGH, $0.03 \mathrm{mg} / \mathrm{kg}$} & $0.75(-2.0: 3.5)$ \\
\hline$T_{\max }(\mathrm{h})$ & $3.40(2.2: 4.6)$ & 2.90 (2.1: 3.7) & $3.88(-12.2: 19.9)$ \\
\hline$C_{\max }(\mu \mathrm{g} / \mathrm{l})$ & 23.8 (16.7: 30.9) & 28.2 (21.2: 35.2) & $22.7(-1.3: 46.7)$ \\
\hline$A \cup C(\mu g / l h)$ & 147 (117.2: 176.8) & 172 (139.1: 204.9) & 147 (123.0: 171.0) \\
\hline$T_{1 / 2}(\mathrm{~h})$ & $2.47(2.0: 3.0)$ & $2.81(2.2: 3.4)$ & $2.63(2.1: 3.2)$ \\
\hline \multicolumn{4}{|l|}{ LB03002, first dose } \\
\hline$T_{\max }(\mathrm{h})$ & $13.2(6.1: 20.3)$ & $12.9(7.7: 18.1)$ & $21.0(12.4: 29.6)$ \\
\hline$C_{\max }(\mu \mathrm{g} / \mathrm{l})$ & 32.8 (19.5: 46.1) & 81.9 (55.5: 108.3) & 87.4 (50.7: 124.1) \\
\hline AUC/dose & $111(-45.2: 267.2)$ & 123 (90.7: 155.3) & 114 (93.8: 134.2) \\
\hline$T_{1 / 2}(\mathrm{~h})$ & $12.0(-11.5: 35.5)$ & $9.29(6.9: 11.6)$ & $11.0(9.1: 12.9)$ \\
\hline \multicolumn{4}{|l|}{ LB03002, last dose } \\
\hline$T_{\max }(\mathrm{h})$ & $10.5(6.7: 14.3)$ & $14.4(6.1: 22.7)$ & 17.6 (11.2: 24.0) \\
\hline$C_{\max }(\mu \mathrm{g} / \mathrm{l})$ & $37.2(29.2: 45.2)$ & 74.7 (54.5: 94.9) & $108.6(35.7: 181.5)$ \\
\hline AUC/dose & 118 (46.5: 189.5) & 136 (91.2: 180.8) & 114 (94.3: 133.7) \\
\hline$T_{1 / 2}(\mathrm{~h})$ & $11.6(8.5: 14.7)$ & $10.2(7.7: 12.7)$ & 11.5 (9.0: 14.0) \\
\hline
\end{tabular}

administrations of LB03002 were transformed into SDS. As shown in Fig. 4, mean peak IGF1 SDS values increased in the normal range by the last LB03002 administration at month 3 , while IGFBP3 SDS values were already in the normal range for all the three LB03002 dose groups following the first administration, i.e. within 1 week.

Prolonged LB03002 administration did not result in overstimulation of the IGF1 system; at month 3, i.e. after the 13th dose of the sustained-release formulation, only three patients, one in each dose group, had a $C_{\max }$ IGF1 value $>2.0$ SDS $(0.2 \mathrm{mg} / \mathrm{kg}$ group: $2.41 \mathrm{SDS}$, $0.5 \mathrm{mg} / \mathrm{kg}$ group: $3.37 \mathrm{SDS}$, $0.7 \mathrm{mg} / \mathrm{kg}$ group: 2.93 SDS). In the same patients at the same time points, IGFBP3 SDS values were in the upper normal range (1.43, 2.16 and 0.83 SDS respectively).

\section{Safety}

Ten patients reported 17 adverse events during the study; all were mild to moderate and resolved without specific intervention. Two events of injection site erythema and one event of hyperthermia were considered possibly related to the study drug. Other reported events were hypothyroidism, headache, pain in extremity and abnormal liver function test. No significant changes were observed in the measures of glucose metabolism and in the clinical chemistry panel. One serious adverse event was reported, which was a case of Quincke's oedema in a patient treated with Genotropin; subsequent testing established that the patient was allergic to certain food components and the allergy test on Genotropin was negative. The event was judged as unrelated to the study drug by the investigator and the patient continued Genotropin treatment.

\section{Discussion}

LB03002 is a novel sustained-release rhGH preparation that has previously been shown to produce elevated $\mathrm{GH}$ levels in adult patients with GHD for an extended

Table 3 Serum IGF1 parameters after daily GH administration (day 7 of treatment) and after LB03002 (first and last once-weekly administration) at doses of $0.2,0.5$ and $0.7 \mathrm{mg} / \mathrm{kg}$; values are mean (approximate $95 \% \mathrm{Cl}$ ).

\begin{tabular}{|c|c|c|c|}
\hline & $\begin{array}{l}\text { Group } 1 \\
\text { 0.2. } \mathrm{mg} / \mathrm{kg} \text { dose }(n=10)\end{array}$ & $\begin{array}{c}\text { Group 2 } \\
0.5 \mathrm{mg} / \mathrm{kg} \text { dose }(n=10)\end{array}$ & $\begin{array}{c}\text { Group 3 } \\
0.7 \mathrm{mg} / \mathrm{kg} \text { dose }(n=8)\end{array}$ \\
\hline Pre-treatment $(\mu \mathrm{g} / \mathrm{l})$ & $16.3(2.4: 30.2)$ & 20.2 (7.5: 32.9) & $14.8(4.8: 24.8)$ \\
\hline \multicolumn{4}{|l|}{ Daily rhGH, $0.03 \mathrm{mg} / \mathrm{kg}$} \\
\hline$T_{\max }(\mathrm{h})$ & $11.0(5.1: 16.9)$ & 15.0 (10.9: 20.9) & 10.8 (4.9: 16.7) \\
\hline$C_{\max }(\mu \mathrm{g} / \mathrm{l})$ & 50.2 (12.6: 87.8) & 43.9 (20.2: 67.6) & 54.9 (26.8: 83.0) \\
\hline AUC/day $(\mu \mathrm{g} / \mathrm{l} \mathrm{h} \mathrm{d})$ & 651 (107.7: 1194.3) & 491 (276.6: 705.4) & 583 (256.3: 909.7) \\
\hline \multicolumn{4}{|l|}{ LB03002, first dose } \\
\hline$T_{\max }(\mathrm{h})$ & 50.4 (24.2: 76.6) & 43.2 (40.0: 47.8) & 63.0 (54.2: 71.8) \\
\hline$C_{\max }(\mu \mathrm{g} / \mathrm{l})$ & 81.0 (14.0: 148.0) & 67.9 (39.9: 95.9) & 117.0 (69.1: 164.9) \\
\hline AUC/day $(\mu \mathrm{g} / \mathrm{l} \mathrm{h} \mathrm{d})$ & 876 (31.7: 1720.3) & 791 (386.2: 1195.8) & 1409 (867.8: 1950.2) \\
\hline \multicolumn{4}{|l|}{ LB03002, last dose } \\
\hline$T_{\max }(\mathrm{h})$ & 36.0 (29.8: 42.2) & 42.0 (38.0: 46.0) & 43.5 (39.1: 47.9) \\
\hline$C_{\max }(\mu \mathrm{g} / \mathrm{l})$ & 113 (30.8: 195.2) & 152 (93.5: 210.5) & 164 (80.6: 247.4) \\
\hline AUC/day $(\mu \mathrm{g} / \mathrm{l} \mathrm{h} \mathrm{d})$ & 1340 (276.8: 2403.2) & 1777 (990.2: 2564.8) & 1945 (764.0: 3126.0) \\
\hline
\end{tabular}




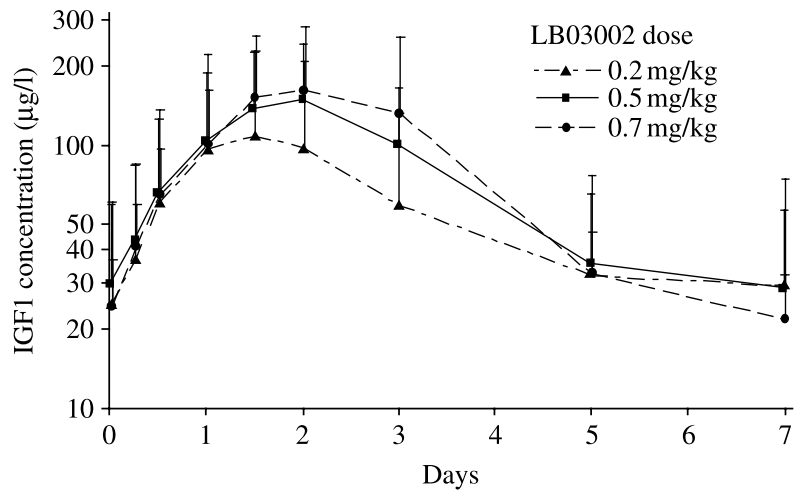

Figure 2 Serum IGF1 levels after weekly administration of LB03002 at doses of $0.2,0.5$ and $0.7 \mathrm{mg} / \mathrm{kg}$ for 3 months; IGF1 levels are plotted on a logarithmic scale as group arithmetic mean +s.D.

period after dosing, with concomitant increases in serum IGF1 and IGFBP3 concentrations (10). The present phase II study in GH-deficient children of prepubertal age shows that LB03002 displays a profile that is comparable with that seen in adults (10); after single LB03002 doses in the range of $0.2-0.7 \mathrm{mg} / \mathrm{kg}$, elevated GH concentrations, with no burst release, are obtained over an extended period ranging from 72 to $120 \mathrm{~h}$, resulting in an AUC that was proportional to the LB03002 dose administered. In addition, mean AUC values after the first and last LB03002 administration did not differ, indicating no accumulation of GH released from the injected preparation over at least a 3-month dosing period. The GH concentration curves indicate that the largest amount of $\mathrm{GH}$ released from the injection site appeared in the bloodstream in the first $48 \mathrm{~h}$ after injection; on the other hand, comparison of the dose-normalised AUCs after LB03002 with AUCs after daily rhGH indicate that $\mathrm{GH}$ exposure after LB03002 is $\sim 75-80 \%$ of that after daily rhGH.

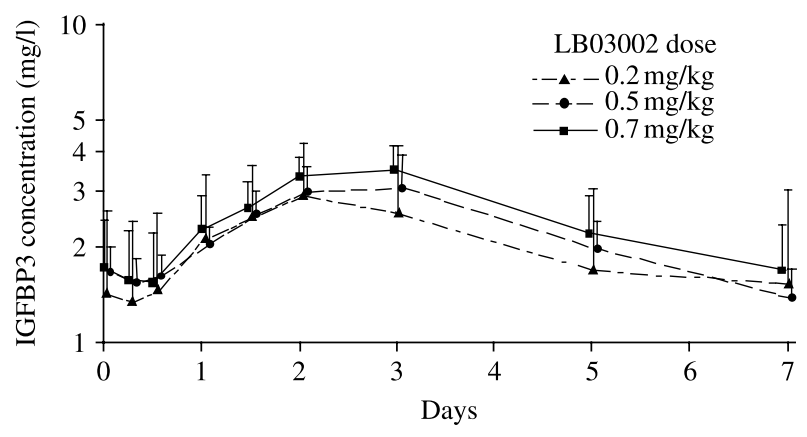

Figure 3 Serum IGFBP3 levels after weekly administration of LB03002 at doses of $0.2,0.5$ and $0.7 \mathrm{mg} / \mathrm{kg}$ for 3 months; IGFBP3 levels are plotted on a logarithmic scale as group arithmetic mean+s.D.
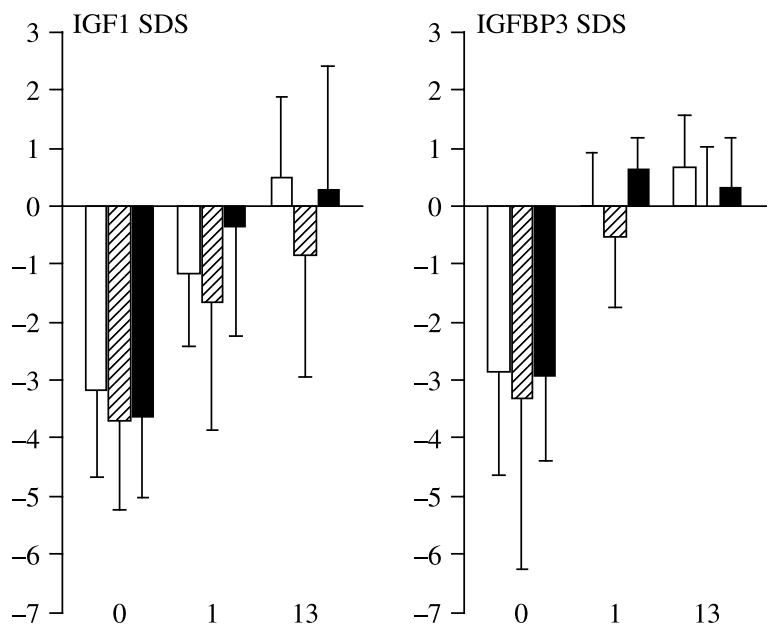

Figure 4 Mean peak IGF1 and IGFBP3 SDS values at baseline and after the first and last (at 3 months) once-weekly administration of LB03002, at doses of 0.2 (open bars), 0.5 (hatched bars) and $0.7 \mathrm{mg} / \mathrm{kg}$ (closed bars). 0, 1 and 13 indicate the study week.

However, this 'estimated relative bioavailability' is higher than the $50 \%$ previously reported for another slow-release formulation, Nutropin Depot (3).

Baseline IGF1 and IGFBP 3 concentrations as well as SDS values were low, indicating that the study population consisted of children with severe GHD. The PD assessment from IGF1 and IGFBP3 measurements revealed a profile consistent with the prolonged $\mathrm{GH}-$ levels and the doses of LB03002 administered. However, the pattern of response of the two parameters to injected LB03002 was different. While IGFBP3 was already normalised after the first dosing (within 1 week), IGF1 showed a slower and more progressive increase and was normalised at the end of the 3 months of continuous LB03002 regimen.

Although based on a limited number of patients, this difference in response of IGF1 and IGFBP3 seems to support observations reported in GH-deficient and SGA children during the IGF1 generation test (13-18). For GH-deficient and SGA children, it was shown that IGF1 levels do not plateau after 1 week of GH treatment and that close to normal IGF1 levels are reached after 3 months of GH administration, while IGFBP3 increased into the normal range much earlier $(17,18)$; a comparable pattern for IGF1 and IGFBP3 is seen in the present study with LB03002. Therefore, we believe that the difference in response time for IGF1 and IGFBP 3 reflects a specific initial response to GH in children with GHD, rather than a specific PD effect related to the sustained-release formulation. With ongoing administration of LB03002, IGF1 levels normalise, indicating that the doses chosen adequately stimulate the IGF system. After 3 months, mean IGF1 and IGFBP3 SDS values were both in the 
normal range, indicating that no overstimulation occurred. Of note, the most pronounced increase in IGF1 level was observed in the same three patients who had the most pronounced increase in IGFBP3. It has been suggested that such a parallelism of response might be considered safe, because a concurrent IGFBP3 rise might prevent an unphysiological high elevation of free IGF1 (19).

In conclusion, we have presented PK and PD data of a new sustained-release rhGH formulation after single and continuous weekly dosing over 3 months in prepubertal GH-naïve children with GHD. The results indicate that, at once-a-week doses of $0.2,0.5$ and $0.7 \mathrm{mg} / \mathrm{kg}$, LB03002 was shown to be safe and well tolerated. Based on the PK and PD profiles obtained, LB03002 is a suitable candidate for investigating longterm treatment to promote growth in $\mathrm{GH}$-deficient, $\mathrm{GH}$ treatment-naïve, pre-pubertal children, and such studies utilising a dose of $0.5 \mathrm{mg} / \mathrm{kg}$ are presently ongoing.

\section{Declaration of interest}

Financial support for this study was provided by BioPartners $\mathrm{GmbH}$, Switzerland, and LG Life Sciences Ltd, South Korea. CS is employed by BioPartners $\mathrm{GmbH}$ and H-JJ is employed by LG Life Sciences. FP, MJ, $\mathrm{MB}$ and PS have each received consultancy fees from BioPartners $\mathrm{GmbH}$.

\section{Funding}

Financial support for this study was provided by BioPartners $\mathrm{GmbH}$, Switzerland, and LG Life Sciences Ltd, South Korea.

\section{Acknowledgements}

The authors are grateful to the investigators and their teams for their commitment in performing this study: Elena BolshovaZubkovskaya, Kiev, Ukraine; Jozsef Kovacs, Szeged, Hungary; A Lewinski and M Hilczer, Lodz, Poland; Ewa Malecka-Tendera, Katowice, Poland; Ferenc Peter, Budapest, Hungary; Valentina Peterkova, Moscow, Russia; Mircea Popa, Bucharest, Romania; Enikö Soliom, Miskolc, Hungary; Jerzy Starzik, Krakow, Poland; Mieczyslaw Walczak, Szczecin, Poland; Dragan Zdravkovic, Beograd, Serbia; Sasa Zivic, Nis, Serbia. The authors would like to thank Influence Medical Communication, UK, for help in preparation of the manuscript.

\section{References}

1 Growth Hormone Research Society. Consensus guidelines for the diagnosis and treatment of growth hormone $(\mathrm{GH})$ deficiency in childhood and adolescence: summary statement of the $\mathrm{GH}$ Research Society. Journal of Clinical Endocrinology and Metabolism 200085 3990-3993.

2 Reiter EO, Attie KM, Moshang T Jr, Silverman BL, Kemp SF, Neuwirth RB, Ford KM \& Saenger P. A multicenter study of the efficacy and safety of sustained release $\mathrm{GH}$ in the treatment of naive pediatric patients with GH deficiency. Journal of Clinical Endocrinology and Metabolism 200186 4700-4706.
3 Kemp SF, Fielder PJ, Attie KM, Blethen SL, Reiter EO, Ford KM, Marian M, Dao LN, Lee HJ \& Saenger P. Pharmacokinetic and pharmacodynamic characteristics of a long-acting growth hormone $(\mathrm{GH})$ preparation (Nutropin Depot) in GH-deficient children. Journal of Clinical Endocrinology and Metabolism 2004 89 3234-3240.

4 Jostel A, Mukherjee A, Alenfall J, Smethurst L \& Shalet SM. A new sustained release preparation of human growth hormone and its pharmacokinetic, pharmacodynamic and safety profile. Clinical Endocrinology 200562 623-627.

5 Silverman BL, Blethen SL, Reiter EO, Attie KM, Neuwirth RB \& Ford KM. A long-acting human growth hormone (Nutropin Depot): efficacy and safety following two years of treatment in children with growth hormone deficiency. Journal of Pediatric Endocrinology and Metabolism 200215 715-722.

6 Teichman SL, Neale A, Lawrence B, Gagnon C, Castaigne JP \& Frohman LA. Prolonged stimulation of growth hormone $(\mathrm{GH})$ and insulin-like growth factor I secretion by CJC-1295, a long-acting analog of GH-releasing hormone, in healthy adults. Journal of Clinical Endocrinology and Metabolism 2006 91 799-805.

7 Munafo A, Nguyen TX, Papasouliotis O, Lecuelle H, Priestley A \& Thorner MO. Polyethylene glycol-conjugated growth hormonereleasing hormone is long acting and stimulates $\mathrm{GH}$ in healthy young and elderly subjects. European Journal of Endocrinology 2005 $153249-256$.

8 Cook DM, Biller BMK, Vance ML, Hoffman AR, Phillips LS, Ford KM, Benzinger DP, Illeperuma A, Blethen SL, Attie KM, Dao LM, Reimann JD \& Fielder PJ. The pharmacokinetic and pharmacodynamic characteristics of a long-acting growth hormone $(\mathrm{GH})$ preparation (Nutropin Depot) in GH-deficient adults. Journal of Clinical Endocrinology and Metabolism 200287 4508-4514.

9 Peterkova V, Arslanoglu I, Bolshova-Zubkovskaya E, Romer T, Zdravkovic D, Kratzsch J, Ji HJ, Savoy C \& Saenger P. A randomized, double-blind study to assess efficacy and safety of valtropin, a biosimilar growth hormone $(\mathrm{GH})$, in children with $\mathrm{GH}$ deficiency. Hormone Research 200768 288-293.

10 Bidlingmeier M, Kim J, Savoy C, Kim MJ, Ebrecht N, de la Motte S \& Strasburger CJ. Comparative pharmacokinetics and pharmacodynamics of a new sustained release growth hormone $(\mathrm{GH})$, LB03002, versus daily GH in adults with GH deficiency. Journal of Clinical Endocrinology and Metabolism $2006 \mathbf{9 1}$ 2926-2930.

11 Brabant G, von zur Muhlen A, Wuster C, Ranke MB, Kratzsch J, Kiess W, Ketelslegers JM, Wilhelmsen L, Hulthen L, Saller B, Mattsson A, Wilde J. Schemer R \& Kann P. Serum insulin-like growth factor I reference values for an automated chemiluminescence immunoassay system: results from a multicenter study. Hormone Research 200360 53-60.

12 Elmlinger MW, Kuhnel W, Weber MM \& Ranke MB. Reference ranges for two automated chemiluminescent assays for serum insulin-like growth factor I (IGF-I) and IGF-binding protein 3 (IGFBP-3). Clinical Chemistry and Laboratory Medicine $2004 \mathbf{4 2}$ 654-664.

13 Buckway CK, Selva KA, Pratt KL, Tjoeng E, Guevara-Aguirre J \& Rosenfeld RG. Insulin-like growth factor binding protein-3 generation as a measure of GH sensitivity. Journal of Clinical Endocrinology and Metabolism 200287 4754-4765.

14 Buckway CK, Guevara-Aguirre J, Pratt KL, Burren CP \& Rosenfeld RG. The IGF-I generation test revisited: a marker of GH sensitivity. Journal of Clinical Endocrinology and Metabolism $2001865176-5183$.

15 Cotterill AM, Camacho-Hubner C, Woods K, Martinelli C, Duquesnoy P \& Savage MO. The insulin-like growth factor I generation test in the investigation of short stature. Acta Paediatrica 1994399 128-130.

16 Blum WF, Cotterill AM, Postel-Vinay MC, Ranke MB, Savage MO \& Wilton P. Improvement of diagnostic criteria in growth hormone insensitivity syndrome: solutions and pitfalls. Pharmacia study 
group on insulin-like growth factor-I treatment in growth hormone insensitivity syndromes. Acta Paediatrica 1994399 117-124.

17 Boguszewski M, Jansson C, Rosberg S \& Albertsson-Wikland K. Changes in serum insulin-like growth factor 1 (IGF-1) and IGF-binding protein-3 levels during growth hormone treatment in pre-pubertal short children born small for gestational age. Journal of Endocrinology and Metabolism 200881 3902-3908.

18 Ranke MB, Traubenecker R, Marti DD, Schweizer R, Schwarze CP, Wollmann HA \& Binder G. IGF-1 and IGF binding protein-3 levels during initial GH dosage step-up are indicators of GH sensitivity in GH-deficient children and short children born small for gestational age. Hormone Research 200564 68-76.

19 Park P \& Cohen P. The role of insulin-like growth factor I monitoring in growth hormone-treated children. Hormone Research 200462 59-65.

Received 20 November 2008

Accepted 10 December 2008 